\title{
COARTAÇÃO DE AORTA EM MULHER JOVEM PORTADORA DE HAS
}

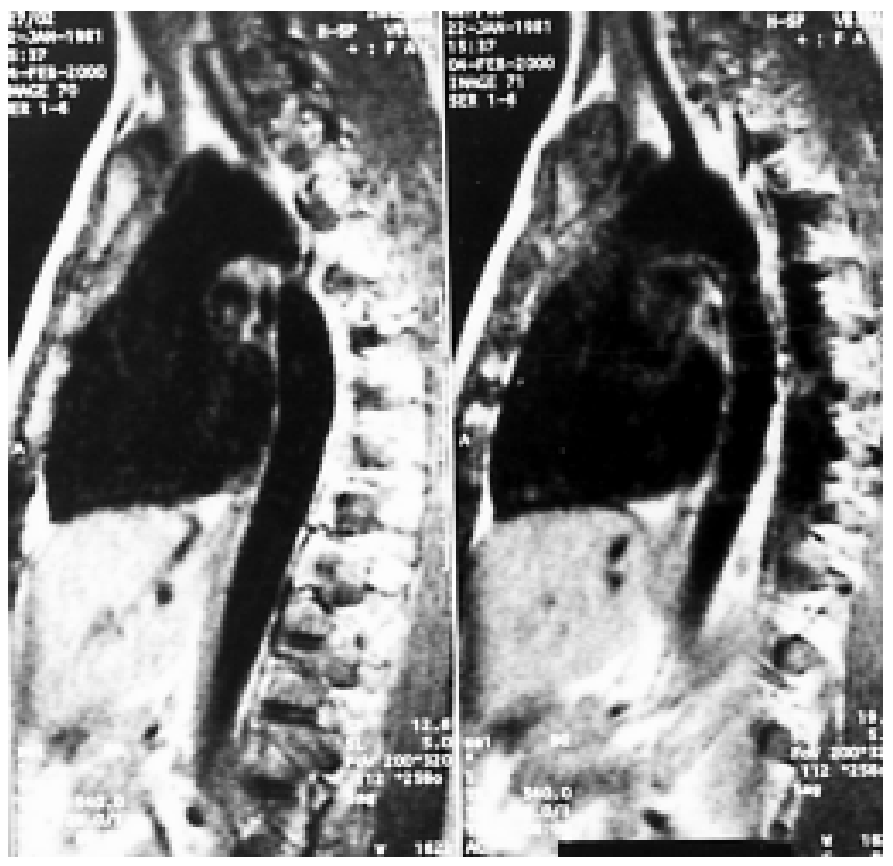

A imagem demonstra a presença de coartação de aorta em mulher jovem ( 8 anos), portadora de HAS (Hipertensão arterial sistêmica), branca, estudante, sem relatos de fatores de risco para doença arterial coronariana e hipertensão arterial sistêmica. Queixas de cefaléia occipital, vertigem, dor precordial, dispnéia, palpitações e dores em membros inferiores desencadeadas pelos esforços.

Ao exame: IMC normal, facies atípica. ACV: pulsos amplos em membros superiores e não palpáveis em membros inferiores. Aorta hiperpulsátil em fúrcula esternal. BI de intensidade normal, B2 com desdobramento fisiológico, estando A2 com intensidade aumentada. Sopro mesossistólico em mesocárdio, irradiado para o dorso. PA em membros superiores: I80x100 mmHg e indetectável em membros inferiores. Exames: I. ECG e Rx normais; 2. Ecocardiograma e RNM: área de estreitamento da aorta descendente, sem anomalias intracardíacas associadas (Figura acima). Estudo hemodinâmico: zona de coartação e gradiente pressórico de $50 \mathrm{mmHg}$ entre as regiões proximal e distal ao estreitamento aórtico. Não houve sucesso com angioplastia e colocação de "Stent", tendo sido indicada cirurgia convencional. Atualmente encontra-se assintomática e normotensa sem uso de medicamentos.

A coartação da aorta localiza-se, com maior freqüência, distal à artéria subclávia esquerda'. É uma das doenças cardíacas congênitas diagnosticadas primariamente na infância ou na adolescência, ${ }^{1,2}$. Quando clinicamente sintomática nos primeiros meses de vida, em geral, manifesta-se por insuficiência cardíaca grave e por vezes refratária, necessitando tratamento cirúrgico precoce 3 . Com freqüência, a coartação da aorta é pouco sintomática ou mesmo assintomática, daí a importância do diagnóstico correto e precoce, a fim de se evitar graves complicações associadas.

\section{Moacyr Magno Palmeira, Inêz Ohashi Torres, Mayana Batista Barros}

\section{Laboratório de Cardiologia da Universidade do Estado do Pará}

Referências

I. Lisboa, Luiz Augusto F., Abreu Filho, Carlos Alberto C., Dallan, Luís Alberto O. et al. Tratamento cirúrgico da coarctação do arco aórtico em adulto: avaliação clínica e angiográfica tardia da técnica extra-anatômica. Rev Bras Cir Cardiovasc 200 I, I6(3): 187-94.

2. Altinbas A; Ozaydin M; Kahraman H; Dogan A. A case with coarctation of the aorta accompanied by coronary ectasia and dilatation of the ascending aorta. Int I Cardiovasc Imaging 2003; 19(3): 185-7.

3. Albuquerque LC, Goldani MA, Goldani J et al. Correção cirúrgica da coartação da aorta nos primeiros seis meses de vida. Rev Bras Cir Cardiovasc 2002; 17(2): 137-43. 